University of Wollongong

Research Online

Faculty of Engineering and Information

Faculty of Engineering and Information

Sciences - Papers: Part A

Sciences

$1-1-2012$

Comparison of methodologies for assessment of harmonic current emission limits for large installations connected to LV networks

Biyanvilage Perera

University of Wollongong, bmdp065@uowmail.edu.au

Sarath Perera

University of Wollongong, sarath@uow.edu.au

Philip Ciufo

University of Wollongong, ciufo@uow.edu.au

Victor J. Gosbell

University of Wollongong, vgosbell@uow.edu.au

Follow this and additional works at: https://ro.uow.edu.au/eispapers

Part of the Engineering Commons, and the Science and Technology Studies Commons

Research Online is the open access institutional repository for the University of Wollongong. For further information contact the UOW Library: research-pubs@uow.edu.au 


\title{
Comparison of methodologies for assessment of harmonic current emission limits for large installations connected to LV networks
}

\author{
Abstract \\ With the proliferation of large, disturbing installations (loads and distribution generators) connected to \\ public low voltage networks, managing the harmonic voltage levels in the network has become a key \\ concern to distribution network service providers (DNSPs). Therefore, it is important that DNSPs limit the \\ harmonic current emission by individual installations. This paper reviews a number of methodologies that \\ exist in the current technical literature in relation to the assessment of harmonic current emission limits \\ for disturbing installations connected to the public LV network. Application of these methodologies is \\ demonstrated through a case study on a test network. The study shows that, though underlying \\ philosophies and data requirements for each of the methodologies vary significantly, they provide a \\ homologous estimation on the emission limits for each individual installation.
}

\section{Keywords}

Iv, current, connected, harmonic, installations, assessment, large, methodologies, comparison, networks, limits, emission

\section{Disciplines \\ Engineering | Science and Technology Studies}

\section{Publication Details}

B. Perera, S. Perera, P. Ciufo \& V. J. Gosbell, "Comparison of methodologies for assessment of harmonic current emission limits for large installations connected to LV networks," in ICHQP 2012: 15th IEEE International Conference on Harmonics and Quality of Power, 2012, pp. 328-335. 


\title{
Comparison of Methodologies for Assessment of Harmonic Current Emission Limits for Large Installations Connected to LV Networks
}

\author{
D. Perera, Student Member, IEEE, S. Perera, Member, IEEE, P. Ciufo, Senior Member, IEEE and \\ V. J. Gosbell, Life Member, IEEE
}

\begin{abstract}
With the proliferation of large, disturbing installations (loads and distribution generators) connected to public low voltage networks, managing the harmonic voltage levels in the network has become a key concern to distribution network service providers (DNSPs). Therefore, it is important that DNSPs limit the harmonic current emission by individual installations. This paper reviews a number of methodologies that exist in the current technical literature in relation to the assessment of harmonic current emission limits for disturbing installations connected to the public LV network. Application of these methodologies is demonstrated through a case study on a test network. The study shows that, though underlying philosophies and data requirements for each of the methodologies vary significantly, they provide a homologous estimation on the emission limits for each individual installation.
\end{abstract}

Index Terms-LV network; distribution generators; harmonic current emission limits

\section{INTRODUCTION}

The connection of both appliances and installations with power electronic front-ends to the power distribution network continues to increase [1]. As a result of the relationship between network impedances and harmonic currents drawn by such equipment and installations, excessive harmonic voltages can be developed that could adversely affect the performance of various customer and utility equipment. Thus, managing network harmonic levels has become a key issue to the DNSPs.

In many countries, harmonic current emission levels in the LV network are governed by product level standards (e.g. IEC 61000-3-2 for equipment with rated current $16 \mathrm{~A}$ or below and IEC 61000-3-12 for equipment with rated current $16 \mathrm{~A}$ to $75 \mathrm{~A})$. Equipment that comply with these standards can be connected to the LV network without further investigation. However, the connection of large installations and distribution generators to the LV network are subject to the approval of the DNSP. Therefore, it is important that the DNSPs have carefully designed guidelines to assess a given installation in relation

D. Perera, S. Perera, P. Ciufo and V.J. Gosbell are with the School of Electrical, Computer and Telecommunications Engineering, University of Wollongong, and are Members of the Endeavour Energy Power Quality and Reliability Centre, NSW 2522, Australia (email:sarath@uow.edu.au).

NOTICE: this is the authors' version of a work that was accepted for publication in the ICHQP proceedings. Changes resulting from the publishing process, such as peer review, editing, corrections, structural formatting, and other quality control mechanisms may not be reflected in this document Changes may have been made to this work since it was submitted for publication. A definitive version was subsequently published in the Proceedings of the 15th IEEE International Conference on Harmonics and Quality of Power June 2012, DOI:10.1109/ICHQP.2012.6381179 to harmonic compatibility. A number of methodologies are reported in the present technical literature for the assessment of harmonic current emission limits for large installations connected to LV networks. Some of these methodologies are detailed in the following technical reports and recommended practices:

- IEC 61000-3-14 technical report (TR) "Assessment of emission limits for the connection of disturbing installations to LV power systems" [2].

- "Technical Rules for the Assessment of Network Disturbances", technical report [3] which is used by DNSPs in Austria, Switzerland, Germany and Czech Republic.

- IEEE 519-1992 "IEEE Recommended Practices and Requirements for Harmonic Control in Electrical Power Systems" [4].

In addition, a novel approach based on the concept of voltage droop [5] is currently being developed in Australia.

The objective of the current research is to review these approaches in relation to the assessment of harmonic current emission limits for large installations connected to $\mathrm{LV}$ networks and compare the range of outcomes. This paper is structured as follows. In Section II some key concepts given in the IEC 61000 series of technical reports and standards in relation to electromagnetic compatibility (EMC) co-ordination in power systems are discussed. Sections III to VI summarise the methodologies for the assessment of harmonic current emission limits given by IEC 61000-3-14 TR, “Technical Rules for the Assessment of Network Disturbances" TR, the voltage droop concept and the IEEE 519 standard respectively. Section VII illustrates the application of these methodologies to a typical LV network in Australia. Section VIII presents the outcome of the case study and a critical discussion on the various methodologies.

\section{BASIC CONCEPTS OF EMC COORDINATION}

\section{A. Compatibility levels and planning levels}

In the EMC co-ordination process for power systems, the compatibility between system disturbance levels and equipment immunity levels is ensured by providing reference values known as compatibility level values [6]. These values are determined based on the $95 \%$ probability of disturbances in the entire power system. The compatibility values of harmonic voltages for public LV network are given in [6]. Based on the compatibility level values, planning level values are defined. 
Planning level values are considered as internal quality objectives of respective DNSPs and depend on the structure of the network. Thus, only indicative values are provided in the technical literature [7]. Planning level values should always be equal to or lower than the compatibility level values.

\section{B. Representation of harmonic sources}

Harmonic variations are best represented by measurement over a period of time to account for time variations and statistical characteristics. Following general concepts are used to represent the interaction of multiple and time-varying harmonic sources:

- All harmonic quantities (voltages and currents) are represented by their $95 \%$ values.

- The resulting magnitude of the harmonic quantity (D) after the aggregation of different sources is obtained through a general summation law given by (1) [2]:

$$
D=\sqrt[\alpha]{\sum D_{i}^{\alpha}}
$$

where $D_{i}$ is the magnitude of the distortion caused by an individual source and $\alpha$ is the summation law exponent. Typical values of $\alpha$ for low order harmonics are given in Table I [2].

TABLE I

TYPICAL SUMMATION EXPONENT VALUES FOR HARMONICS

\begin{tabular}{|c|c|c|c|}
\hline Harmonic order & $h<5$ & $h \leq 10$ & $h>10$ \\
\hline$\alpha$ & 1 & 1.4 & 2 \\
\hline
\end{tabular}

\section{IEC 61000-3-14 - “ASSESSMENT OF EMISSION LIMITS} FOR THE CONNECTION OF DISTURBING INSTALLATIONS TO LV POWER SYSTEMS" (TR)

The IEC 61000-3-14 TR provides a methodology for the assessment of harmonic current emission limits for individual installations connected to radial LV systems, based on the EMC concepts discussed in Section II. A simplified scheme of a radial LV network is given in Fig. 1. Three stages of evaluation which can be applied either in sequence or independently [2] [8], are defined for the assessment of emission limits.

Stage 1: Small installations, such as residential houses, whose size is less than the minimum value $\left(S_{\min }\right)$ defined by the DNSP, can be connected to the supply network without any further investigation. In such cases, the DNSP will rely on the product family standards [9] [10] to limit the impact of harmonic emission on the network. Therefore, the selection

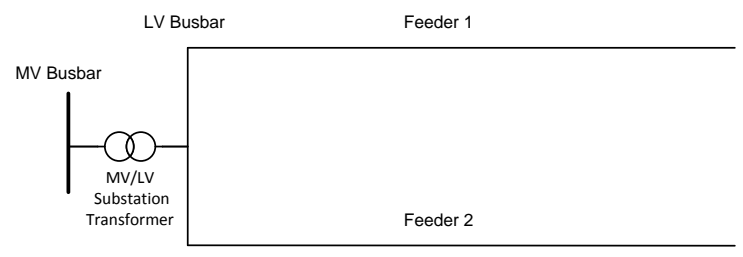

Fig. 1. Simplified scheme of a radial LV system of $S_{\min }$ is a compromise between limiting the number of installations of which emissions need to be assessed and keeping the network harmonic emissions within acceptable limits. In addition, connection of an installation can be allowed under Stage 1, if the following conditions are met:

- the customer does not use power factor correction capacitors and/or harmonic filters;

- the ratio between the VA capacity $\left(S_{i}\right)$ of the installation to short circuit level $\left(S_{s c}\right)$ at the point of evaluation is less than $1 \%$;

- for each harmonic order, the harmonic current emission is smaller than the limit defined by the DNSP according to the network characteristics. The TR does not provide procedures for evaluating the harmonic current emission limit. However, indicative values are provided and are given in Table II [2].

TABLE II

INDICATIVE VALUES FOR HARMONIC CURRENT EMISSION LIMITS FOR STAGE 1 ASSESSMENT

\begin{tabular}{|l|c|c|c|c|c|c|c|}
\hline Harmonic order & 3 & 5 & 7 & 9 & 11 & 13 & $13<\mathrm{h} \leq 40$ \\
\hline $\begin{array}{l}\text { Harmonic current } \\
\text { emission limit as \% of } \\
\text { rated current }\end{array}$ & 4 & 5 & 5 & 1 & 3 & 3 & $\frac{500}{h^{2}}$ \\
\hline
\end{tabular}

Stage 2: For large installations $\left(S_{i}>S_{\min }\right)$ that do not comply with Stage 1, higher harmonic current emission limits are allowed based on the network harmonic absorption capacity, the capacity of the installation and the network characteristics. The underlying concept of this approach is that, if the network is fully utilised to its capacity and if all installations inject up to their allocated limits, the net harmonic voltage value at the end of a feeder should be equal to the planning level values. The total harmonic voltage at the LV level, is the combination of harmonic voltages propagating from the upstream MV network and the contribution from the harmonic loads connected to the considered LV network. Therefore, the maximum acceptable global contribution of harmonic voltage to the LV level $\left(G_{h L V}\right)$ is given by (2) [2]:

$$
G_{h L V}=\sqrt[\alpha]{L_{h L V}^{\alpha}-\left(T_{h M L} L_{h M V}\right)^{\alpha}}
$$

where $L_{h M V}, L_{h L V}$ and $T_{h M L}$ are the MV planning level, the LV planning level and the transfer coefficient from the upstream MV network to the LV network for the $h^{\text {th }}$ order harmonic respectively.

Based on the value of $G_{h L V}$, individual current emission limit values are defined, subject to the following two conditions:

- the global contribution of all small and large installations to the harmonic voltage at any point of the network should not exceed $G_{h L V}$

- the global contribution of all small and large installations to the harmonic voltage at the substation LV busbar should not exceed maximum acceptable global contribution $\left(G_{h B}\right)$ value given by (3) [2]:

$$
G_{h B}=K_{h B} G_{h L V}
$$


where $K_{h B}$ is a reduction factor which takes into account the contribution of harmonic voltage caused by small installations only, at the LV busbar. This factor is calculated by assuming that the entire network is fully loaded with small installations only and is given by (4) [2]:

$$
K_{h B}=\frac{U_{h B}\left(S_{t}\right)}{\max \left(U_{h L V}\left(S_{t}\right)\right)}
$$

where;

- $U_{h B}\left(S_{t}\right)$ is the global contribution of all installations, to the harmonic voltage of order $h$ at the substation LV busbar, and

- $\max \left(U_{h L V}\left(S_{t}\right)\right)$ is the maximum value of the global contribution of all installations, to the harmonic voltage of order $h$ at any point in the considered LV system.

A methodology for estimating the $K_{h B}$ value is given in the TR [2]. The reader should note that if the considered network has no small installations, then $K_{h B}=1$.

The harmonic current emission limit for an individual installation, $i$, is given by (5) [2]:

$$
E_{I h i}=G_{h L V} \sqrt[\alpha]{\frac{S_{i}}{S_{t}}} \min \left(\frac{K_{h B}}{Z_{h B}}, \frac{1}{Z_{h i}}\right)
$$

where:

- $E_{I h i}$ is the harmonic current emission limit for the installation $i$,

- $S_{i}$ is the VA capacity of the installation $i$,

- $S_{t}$ is the total system VA capacity of the considered LV network,

- $Z_{h B}$ is the harmonic impedance at the LV busbar,

- $Z_{h i}$ is the harmonic impedance at the point of evaluation of the customer installation $i$.

The capacity of distribution generation (DG) connected to the considered LV network should be taken into account when determining the total system capacity $\left(S_{t}\right)$. For instance, if an $\mathrm{LV}$ network has $50 \%$ level of penetration by DG sources, $S_{t}$ should be adjusted to $150 \%$ of the MV/LV transformer capacity.

Stage 3: On some occasions, connection of an installation which will fails to comply under Stage 2 is accepted at a higher emission level under a conditional basis. This is particularly the case, when the parameters used under Stage 2 are conservative and there is some unused disturbance absorption capacity of the network that can be used on a temporary basis. Connection of an installation under Stage 3 will require conducting a detailed study to determine the preexisting harmonic levels and the expected contribution of the considered installation.

For the assessment of harmonic current emission limits, DG installations can be considered as disturbing installations. Thus, the methodology discussed in this section can be applied. Correspondingly, $S_{t}$ needs to be adjusted to take into account the presence of DG sources as in Stage 2.

\section{IV. "TECHNiCAl Rules FOR THE Assessment of NETWORK DisTURBANCES"}

The "Technical Rules for the Assessment of Network Disturbances" provides an alternative methodology for harmonic emission allocation for large disturbing installations connected to the LV network. The proposed methodology follows the same philosophy as IEC 61000-3-14 (e.g. compatibility levels) [11] [12], but provides a simplistic and efficient approach in the emission co-ordination process.

Assessment of emission limits for an installation is carried out in three steps:

Step 1: The ratio of the short-circuit level $\left(S_{s c}\right)$ at the point of common coupling to the agreed power of the installation $\left(S_{i}\right)$ is assessed. If $S_{s c} / S_{i} \geq 150$, the connection of the installation is accepted, and calculation of emission limits is not required.

Step 2: The ratio of the harmonic load $\left(S_{O S}\right)$ to the agreed power of the installation $\left(S_{i}\right)$ is determined. In order to determine $S_{O S}$, each load in the installation is grouped into one of the three categories based on the total harmonic current distortion (THD).

- Loads with $\mathrm{THD}_{i}<10 \%$, are not considered in determining $S_{O S}$.

- Loads with $10 \% \leq \mathrm{THD}_{i} \leq 25 \%$, are grouped as group one and their capacity $\left(S_{\mathrm{Gr} .1}\right)$ is determined.

- Loads with $\mathrm{THD}_{i} \geq 25 \%$, are grouped as group two and their capacity $\left(S_{\mathrm{Gr} .2}\right)$ is determined.

Considering the diversity of each load, the total $S_{O S}$ value is calculated by (6) [3].

$$
S_{O S}=0.5 \cdot S_{\mathrm{Gr} .1}+S_{\mathrm{Gr} .2}
$$

No distinction is made between the active power and the apparent power of the installation when determining $S_{O S}$ [3].

Step 3: The ratio of the harmonic load to the agreed power of the installation $\left(S_{O S} / S_{i}\right)$ is examined, subject to the following two conditions:

- if $\left(S_{O S} / S_{i}\right) \leq 0.082 \cdot \sqrt{S_{s c} / S_{i}}$, the connection is approved and the calculation of emission limits is not required;

- if $\left(S_{O S} / S_{i}\right) \geq 0.082 \cdot \sqrt{S_{s c} / S_{i}}$, remedial measures should be employed to limit the emission such that the allocation is not exceeded.

Emission allocation limits $\left(E_{I h i}\right)$, in amperes, for a large installation $i$, are determined by (7) (adapted from [3]):

$$
\frac{E_{I h i}}{I_{A}} \leq \frac{p_{h}}{1000} \cdot \sqrt{\frac{S_{s c}}{S_{i}}}
$$

where $I_{A}$ is the rated current of the installation calculated based on the agreed power of the installation. The proportionality factor $\left(p_{h}\right)$ takes into account the permissible maximum harmonic voltage contribution at the LV busbar for the $h^{\text {th }}$ order harmonic. Typical values of $p_{h}$ for converter specific harmonics are given in Table III.

In addition, a total harmonic distortion factor $\left(\mathrm{THD}_{I_{A}}\right)$ for the considered installation can be evaluated by (8) (adapted from [3]): 
TABLE III

PROPORTIONALITY FACTOR VALUES $\left(p_{h}\right)$ FOR CONVERTER TYPICAL HARMONICS (ADAPTED FROM [3])

\begin{tabular}{|c|c|c|c|c|c|c|c|c|}
\hline$h$ & 3 & 5 & 7 & 11 & 13 & 17 & 19 & $¿ 19$ \\
\hline$p_{h}$ & $6\left(18^{*}\right)$ & 15 & 10 & 5 & 4 & 2 & 1.5 & 1 \\
\hline & value for determining the harmonic current limit
\end{tabular}

in the neutral conductor.

$$
\operatorname{THD}_{I_{A}}=\frac{\sqrt{\sum_{h=2}^{50} I_{h}^{2}}}{I_{A}} \leq \frac{20}{1000} \cdot \sqrt{\frac{S_{s c}}{S_{i}}}
$$

For distribution generators, emission limits are defined only if power in-feed takes place via power electronic front-ends. For such installations, $50 \%$ of emission limits defined in this section are provided.

\section{Voltage Droop Method}

The voltage droop method provides a harmonic allocation methodology applicable to installations at both MV and LV levels [5] [13]. Voltage droop is defined as the summation of all individual voltage drops in the distribution network between the transmission system, represented by a Thévenin voltage source, and the network point being considered [5]. The philosophy of the voltage droop method is that the $h^{\text {th }}$ harmonic impedance of the network is $h$ times the fundamental reactance. Thus, the voltage drop of the network at the $h^{\text {th }}$ harmonic is proportional to the fundamental voltage drop. Therefore, the maximum harmonic voltage in the network which would occur at the end of the most heavily loaded LV feeder, is proportional to $h$ times the voltage droop limit [13]. This assumption will only be valid if the resistive component of the network impedance is negligible when compared to the reactive component of the network impedance. The data requirements for the application of this methodology are only the maximum demand $\left(S_{i}\right)$ of load and the fundamental reactance at the point of common coupling $\left(x_{i 1}\right)$.

The emission allocation limit for non-triplen harmonics of order $h$ for installation $i$ is given by (9) [14],

$$
E_{I h i}=k_{h} \cdot \frac{S_{i}^{1 / \alpha}}{x_{i 1}^{1-1 / \alpha}}
$$

and $k_{h}$ is given by (10) [14]:

$$
k_{h}=\frac{L_{L V h}}{h \cdot V_{\mathrm{droop}}^{1 / \alpha}}
$$

where $V_{\text {droop }}$ is the maximum system voltage droop which is $30-40 \%$ pu [14] for typical Australian networks. The voltage droop methodology does not provide emission limits for DG, but rather relies on maintaining a safety margin between the maximum harmonic voltage (that would occur when limits are derived from the voltage droop methodology) and the planning limits, which could be used by DG [13].

\section{IEEE 519 - "IEEE RECOMMENDED PRACTICES AND REQUIREMENTS FOR HARMONIC CONTROL IN Electrical POWER Systems"}

The IEEE 519 standard provides harmonic-current emission limits for large installations in terms of the ratio between the maximum short circuit current $\left(I_{s c}\right)$ at the point of common coupling and the maximum demand load current $\left(I_{L}\right)$ of the installation. These emission limits are based on (11) [15]:

$$
I_{h}=\frac{V_{h}}{h \cdot Z_{s c} \cdot \sigma}
$$

where $V_{h}$ is the maximum harmonic voltage allowed at the connection point [4] and $Z_{s c}$ is the short circuit impedance of the system at the point of connection. The aggregation factor, $\sigma$, takes into account the maximum number of installations connected to the same point of coupling, the ratio of the short circuit current to the maximum demand customer load current and the diversity between different order harmonics.

Harmonic current emission limits for installations connected to voltages between $120 \mathrm{~V}$ and $69,000 \mathrm{~V}$, are given in Table IV. [4] recommends that $I_{L}$ be calculated from the maximum demand for the preceding 12 months. The limits given in Table IV are to be observed under the worst case of normal operation (conditions lasting for longer than one hour) of the installation. However, the limits are allowed to exceed by $50 \%$ for shorter periods, during start-ups and other unusual conditions. Even harmonics are restrained to $25 \%$ of the values indicated for odd harmonics in Table IV. Harmonic current emission limits for all distribution generators connected to $\mathrm{LV}$ networks are restricted to limits corresponding to $I_{s c} / I_{L}<20$, regardless of the actual $I_{s c} / I_{L}$ at the point of connection of the generators.

\section{APPLICATION EXAMPLE OF THE ASSESSMENT OF HARMONIC CURRENT EMISSION LIMITS}

A new office building with an agreed power of $100 \mathrm{kVA}$, consisting of linear and non-linear loads and other installations, is to be connected to a 3-phase, LV network, $150 \mathrm{~m}$ from the MV/LV transformer. The following non-linear devices and installations will be in operation in the building [3].

- 18 computers each with $500 \mathrm{VA}$

- 30 monitors each with $200 \mathrm{VA}$

- 15 terminals each with 300 VA

- 5 printers each with $800 \mathrm{VA}$

- Fax machine 500 VA

- UPS-system for central computer $10 \mathrm{kVA}$

- Fluorescent lamp system 10 kVA

- Lift with 3-phase AC power controller of $5 \mathrm{kVA}$

- Air conditioning unit with converter of $9 \mathrm{kVA}$

The parameters of the considered LV network, which are based on a typical Australian LV system are as follows. The MV/LV transformer has a capacity of $315 \mathrm{kVA}$ and an impedance of $(0.006+j 0.022) \Omega$ referred to the $\mathrm{LV}$ side. The network consists of two feeders, each $250 \mathrm{~m}$ long. The phase and neutral conductor impedances are both $(0.315+$ j0.259) $\Omega / \mathrm{km}$. The methodologies discussed in Section III to 
TABLE IV

HARMONIC CURRENT DISTORTION LIMITS FOR GENERAL DISTRIBUTION SYSTEMS 120 V THROUGH 69 KV [4]

\begin{tabular}{|l|l|c|c|c|c|c|}
\hline \multicolumn{7}{|c|}{ Maximum Harmonic Current Distortion in Percent of $I_{L}$} \\
\hline \multicolumn{7}{|c|}{ Individual Harmonic Order (Odd Harmonics) } \\
\hline$I_{s c} / I_{L}$ & $h<11$ & $11 \leq h<17$ & $17 \leq h<23$ & $23 \leq h<35$ & $35 \leq h$ & TDD \\
\hline$<20$ & 4.0 & 2.0 & 1.5 & 0.6 & 0.3 & 5.0 \\
\hline $20<50$ & 7.0 & 3.5 & 2.5 & 1.0 & 0.5 & 8.0 \\
\hline $50<100$ & 10.0 & 4.5 & 4.0 & 1.5 & 0.7 & 12.0 \\
\hline $100<1000$ & 12.0 & 5.5 & 5.0 & 2.0 & 1.0 & 15.0 \\
\hline$>1000$ & 15.0 & 7.0 & 6.0 & 2.5 & 1.4 & 20.0 \\
\hline
\end{tabular}

VI are used to determine the harmonic emission limits for the installation.

1) IEC 61000-3-14: Under Stage 1, the DNSP needs to determine the minimum size for a large installations. In the considered case, $S_{\min }$ is assumed to be $30 \mathrm{kVA}$. Since the agreed power of the considered installation exceeds $30 \mathrm{kVA}$, the ratio of the capacity of the installation to the short circuit level at the point of common coupling of the installation needs to be calculated in order to determine whether the installation can be accepted under Stage 1. As the short circuit power $S_{s c, i}$ at the point of connection is mainly determined by the impedance of the MV/LV transformer and low voltage line impedance:

$$
\begin{gathered}
S_{s c, i}=\frac{U_{n}^{2}}{Z_{i}}=\frac{(0.4)^{2}}{(0.006+j 0.022)+(0.315+j 0.259) \cdot 0.150} \\
=1.979 \mathrm{MVA}
\end{gathered}
$$

Since the $S_{i} / S_{s c, i}$ ratio is greater than $1 \%$, the connection of the installation cannot be accepted under Stage 1. Therefore, the DNSP will need to evaluate the emission limits based on Stage 2 methodology. The parameter values presented in Table V are used for the evaluation of Stage 2 emission limits. Emission limits based on Stage 2 allocation methodology for the considered installation are given in Table VI.

TABLE V

PARAMETERS FOR APPLICATION OF IEC 61000-3-14 STAGE 2 ALLOCATION METHODOLOGY

\begin{tabular}{|l|c|c|c|c|c|}
\hline$h$ & 3 & 5 & 7 & 11 & 13 \\
\hline$L_{h M V}$ & 0.04 & 0.05 & 0.04 & 0.03 & 0.025 \\
\hline$L_{h L V}$ & 0.05 & 0.06 & 0.05 & 0.035 & 0.03 \\
\hline$T_{h M L}$ & 1.0 & 1.0 & 1.0 & 1.0 & 1.0 \\
\hline$\alpha$ & 1.0 & 1.4 & 1.4 & 2.0 & 2.0 \\
\hline$G_{h L V}$ & 0.010 & 0.021 & 0.020 & 0.018 & 0.017 \\
\hline$K_{h B}$ & 0.22 & 0.53 & 0.53 & 0.53 & 0.53 \\
\hline$Z_{h B}$ & 0.066 & 0.110 & 0.154 & 0.242 & 0.286 \\
\hline$Z_{h i}$ & 0.567 & 0.309 & 0.429 & 0.672 & 0.793 \\
\hline
\end{tabular}

TABLE VI

HARMONIC CURRENT LIMITS BASED ON IEC 61000-3-14

\begin{tabular}{|l|c|c|c|c|c|}
\hline$h$ & 3 & 5 & 7 & 11 & 13 \\
\hline$E_{I h i}(\mathrm{~A})$ & 1.29 & 6.82 & 4.63 & 3.49 & 2.72 \\
\hline
\end{tabular}

2) Technical Rules for the Assessment of Network Disturbances: The ratio of the short circuit power at the point of common coupling to the capacity of the installation can be calculated as:

$$
\frac{S_{s c, i}}{S_{i}}=\frac{1979}{100} \leq 150
$$

Since $S_{s c, i} / S_{i}$ ratio is less than 150, a comprehensive assessment is required. Therefore, each load within the installation is grouped according Table VII.

TABLE VII

HARMONIC LOAD OF THE INSTALLATION

\begin{tabular}{|l|c|c|}
\hline Devices/installation & Group 1 & Group 2 \\
\hline 18 Computers & & $9 \mathrm{kVA}$ \\
\hline 30 Monitors & & $6 \mathrm{kVA}$ \\
\hline 15 Terminals & & $4.5 \mathrm{kVA}$ \\
\hline 5 Printers & & $4 \mathrm{kVA}$ \\
\hline Fax machines & & $0.5 \mathrm{kVA}$ \\
\hline UPS system & & $10 \mathrm{kVA}$ \\
\hline Lighting system & $10 \mathrm{kVA}$ & \\
\hline Lift & & $5 \mathrm{kVA}$ \\
\hline Air-conditioning & & $9 \mathrm{kVA}$ \\
\hline Sum & $S_{G r .1}=10 \mathrm{kVA}$ & $S_{G r .2}=48 \mathrm{kVA}$ \\
\hline
\end{tabular}

Then the total harmonic load of the installation $S_{O S, i}$ is calculated:

$$
S_{O S, i}=0.5 \cdot S_{\mathrm{Gr} .1}+S_{\mathrm{Gr} .2}=53 \mathrm{kVA}
$$

The resulting harmonic load ratio $S_{O S, i} / S_{i}=0.53$ exceeds $0.082 \cdot \sqrt{S_{s c, i} / S_{i}}=0.378$. Therefore, the connection of the installation is accepted, only if remedial measures are employed to limit the harmonic currents to values indicated in Table VIII.

TABLE VIII

HARMONIC CURRENT LIMITS BASED ON “TECHNICAL RULES FOR THE ASSESSMENT OF NETWORK DisturbanCES"

\begin{tabular}{|l|c|c|c|c|c|}
\hline$h$ & 3 & 5 & 7 & 11 & 13 \\
\hline$E_{I h i}(\mathrm{~A})$ & $3.85\left(11.55^{*}\right)$ & 9.63 & 6.42 & 3.21 & 2.57 \\
\hline
\end{tabular}

The admissible $\mathrm{THD}_{I_{A}}$ limit for the installation is given by:

$$
\operatorname{THD}_{I_{A}}=\frac{20}{1000} \cdot \sqrt{\frac{S_{s c}}{S_{i}}}=\frac{20}{1000} \cdot \sqrt{19.79}=8.90 \%
$$

3) Voltage Droop: Harmonic current limits, derived from the voltage droop method are given in Table IX. The $k_{h}$ values are determined subject to a maximum system voltage droop of $30 \%$, which is typical for Australian LV networks and LV compatibility levels [6]. 
TABLE IX

HARMONIC CURRENT LIMITS BASED ON VOLTAGE DROOP METHODOLOGY

\begin{tabular}{|l|c|c|c|c|}
\hline$h$ & 5 & 7 & 11 & 13 \\
\hline$k_{h}$ & 0.028 & 0.017 & 0.006 & 0.004 \\
\hline$E_{\text {Ihi }}(\mathrm{A})$ & 10.42 & 6.20 & 4.30 & 3.12 \\
\hline
\end{tabular}

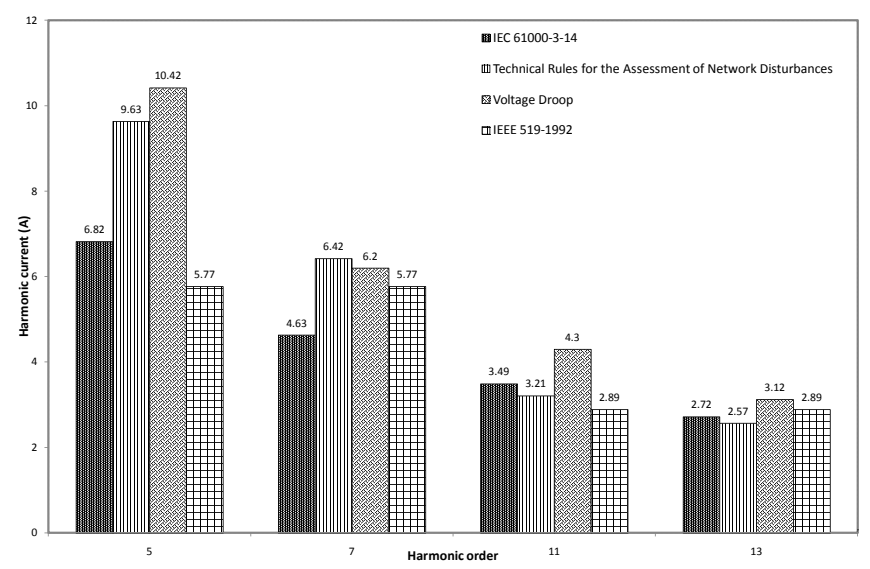

Fig. 2. Harmonic current emission limits for different harmonics for the installation considered in the Section VII

4) IEEE Std 519-1992: IEEE voltage limits are different to the IEC compatibility values which are used in Australia. Therefore the emission limits given by Table IV are adjusted using a scaling factor in order to determine the current emission limits for the considered installation [14]. The calculated current emission limits are given in Table $\mathrm{X}$. The maximum demand load current is calculated based on the agreed power of the installation.

TABLE $X$

HARMONIC CURRENT LIMITS BASED ON IEEE STD 519

\begin{tabular}{|l|c|c|c|c|c|}
\hline$h$ & 3 & 5 & 7 & 11 & 13 \\
\hline Scaling factor & 1.66 & 2.00 & 1.66 & 1.17 & 1.00 \\
\hline$E_{I h i}(\mathrm{~A})$ & 9.62 & 1.56 & 9.62 & 3.37 & 2.89 \\
\hline
\end{tabular}

\section{COMPARISON OF HARMONIC CURRENT ALLOCATION METHODOLOGIES}

A comparison between the harmonic current emission limits for the case study, considered in Section VII is given in Fig. 2. The reader should note that IEC 61000-3-14 TR provides relatively stringent limits for $5^{\text {th }}$ and $7^{\text {th }}$ order harmonics, compared to the "Technical Rules for Assessment of Network Disturbances", the voltage droop and IEEE methodologies.

Fig. 3 compares the harmonic current emission limits derived from the four methodologies discussed, as the point of connection of the installation is moved from a location near to the MV/LV transformer to the end of feeder. It depicts that the harmonic current emission limits for the installation are significantly higher if the installation is connected near the MV/LV transformer than at the end of the feeder of the network as expected. In addition, the reader should observe that the harmonic current limits for $3^{\text {rd }}, 5^{\text {th }}$ and $7^{\text {th }}$ order
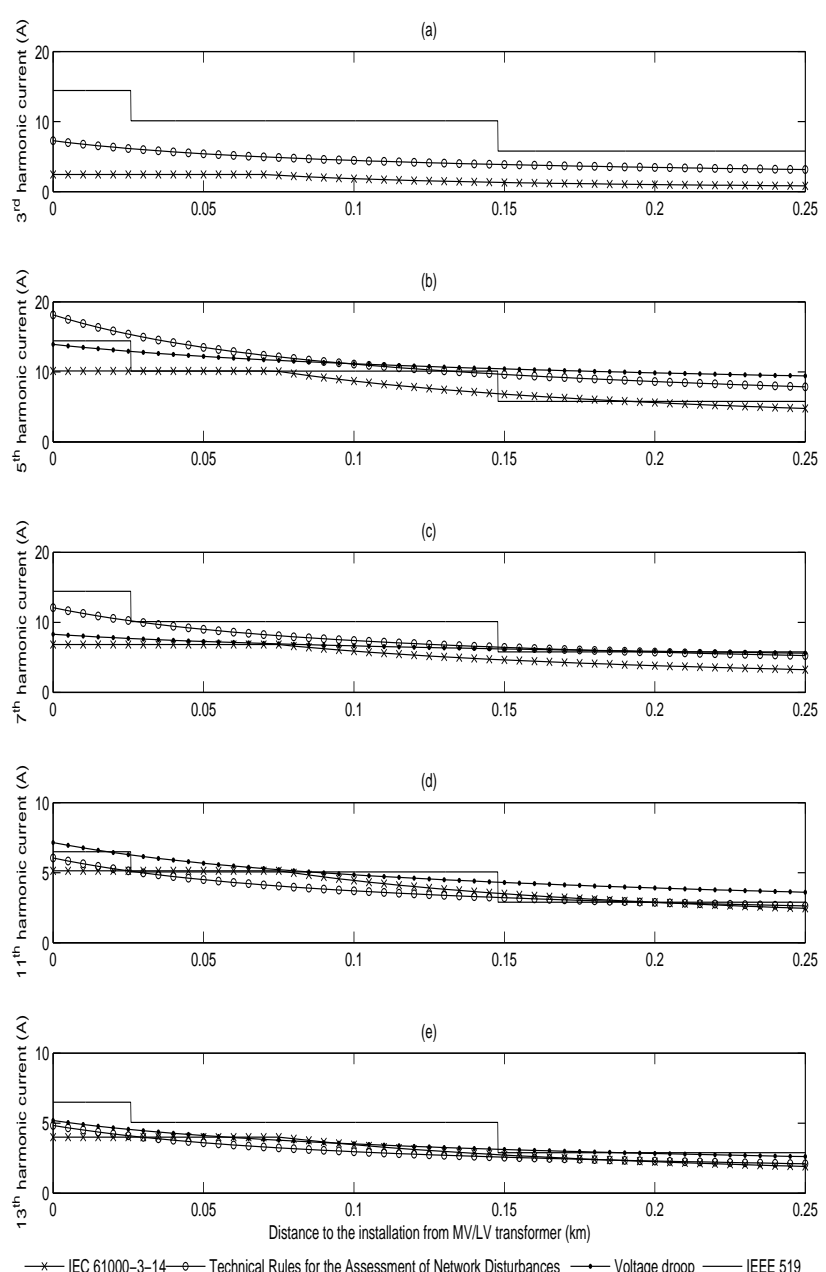

Fig. 3. Emission limits as a function of the distance to the installation from the MV/LV transformer (a) $3^{\text {rd }}$ harmonic current limit, (b) $5^{\text {th }}$ harmonic current limit, (c) $7^{\text {th }}$ harmonic current limit, (d) $11^{\text {th }}$ harmonic current limit, (e) $13^{\text {th }}$ harmonic current limit

harmonics derived from IEEE Std 519 after being adjusted to Australian harmonic voltage compatibility levels are significantly higher compared to the other methodologies discussed in the paper. Furthermore, Fig. 4 provides a comparison between the corresponding $5^{\text {th }}$ harmonic voltage, allocated to the installation as the point of connection of the installation is moved away from a location near the MV/LV transformer to the end of feeder.

In general, the harmonic current limits given by the four methodologies discussed in this paper are derived from the voltage quality targets such that when all installations emit their permissible emission levels, the net harmonic voltages in the network will be within the intended harmonic voltage limits. However, exact agreement between the harmonic current limits cannot be expected, as the driving principles vary between the different methodologies. For instance, the 


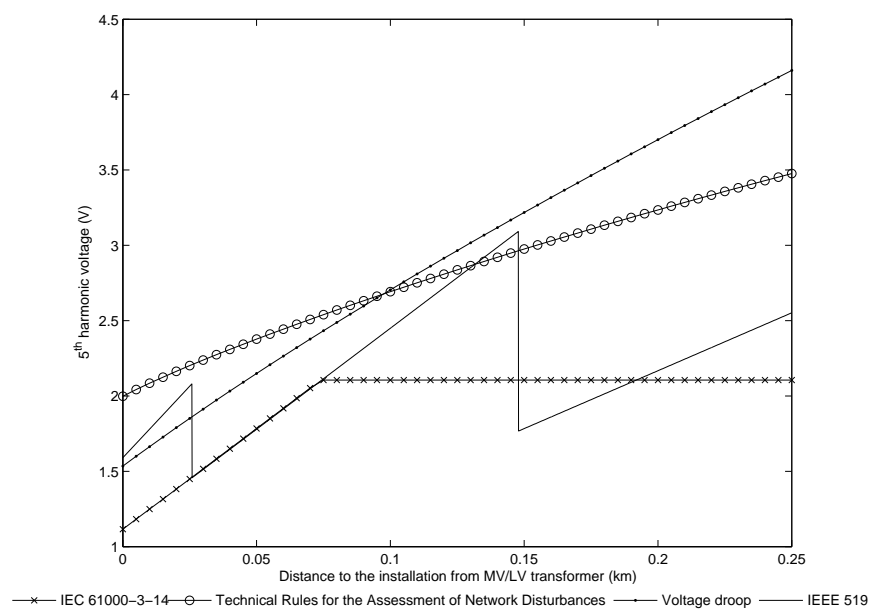

Fig. 4. $5^{\text {th }}$ harmonic voltage allocated to the installation, as a function of the distance to the installation from the MV/LV transformer

IEC 61000-3-14, “Technical Rules for Assessment of Network Disturbances" and voltage droop methods rely on the compatibility level values [6], which decrease with the harmonic order. Voltage distortion limits in IEEE 519 are different from the IEC compatibility values and remain constant over different harmonic orders.

Similarly, the data requirement and ease of application vary between these methodologies. IEC 61000-3-14 provides a flexible methodology for assessment of harmonic limits. However, it requires computation of various factors (e.g. the transfer coefficient and reduction factor) for the network under consideration, which could be problematic. When data is not available, optimal values for these parameters are to be used [2]. Thus, the emission limits could result in conservative values. The methodology presented in "Technical Rules for Assessment of Network Disturbances", takes into account an estimation of harmonic current emission of the considered installation. Thus, large installations which do not emit significant harmonic currents are exempted from application of harmonic current limits. Accordingly, higher harmonic current emissions are allowed for disturbing installations. The data requirement is less compared to the IEC methodology and the required data can be conveniently obtained from the utility and the customer under consideration. The values of the coefficients required to calculate the current limits can be directly obtained from the document providing more transparency between calculations. However procedures to determine the values of coefficients are not given in the document, therefore the application of the methodology for a specific situation would be difficult. The voltage droop methodology provides a more simplistic allocation methodology with lesser amount of computation and assumptions. However, for an LV network, the resistive component of the line impedance is significant. Thus, this methodology provides only an approximation. Therefore, in such situations, the allocation equations should be adjusted to reflect the resistive component of the voltage droop [14]. In addition, the voltage droop method needs further development to assess the triplen-harmonic current limits, as the propagation of triplen-harmonics current is different from the propagation of non-triplen harmonics. The methodology given in IEEE 519 provides a convenient approach to determine harmonic current emission limits compared to other methodologies discussed. However, the methodology is less flexible and difficult to be adapted to networks with different practices.

In addition, the methodologies discussed in this paper do not take into consideration the possible resonance cases that could occur due to large cable networks or non-detuned capacitor banks in the LV network [2] [12] [15]. For cases where resonance might occur, more detailed assessment or simulation will be needed for assessment of harmonic current emission limits.

\section{Conclusions}

A comparison between the harmonic current emission methodologies for large installations connected to the public LV network given in two documents, IEC 61000-3-14 TR, "Technical Rules for Assessment of Network Disturbances" and IEEE Std 519-1992 and an approach based on the voltage droop method was discussed in this paper. Although the assumptions and data requirements of each of these methodologies vary, they provide a good estimation on the emission limits for each individual installation, in order to maintain the voltage quality in the LV network. Exceeding these limits by a particular customer does not necessarily imply that the voltage quality of the network would be affected, but rather provides an indication of a potential problem. Thus, the methodologies discussed in this paper have to be used with intuitive and good engineering judgement to avoid unnecessary expenses related to installation of remedial measures.

\section{APPENDIX A \\ NOMENCLATURE}

\footnotetext{
$E_{I h i} \quad$ Harmonic current emission limit of order $h$ for installation $i$

$G_{h L V} \quad$ Maximum acceptable global contribution to the harmonic voltage of order $h$ anywhere in the LV system

$k_{h} \quad$ Harmonic allocation constant

$K_{h B} \quad$ Reduction factor at harmonic order $h$

$L_{h L V} \quad$ Planning level for harmonic $h$ at $\mathrm{LV}$

$L_{h M V} \quad$ Planning level for harmonic $h$ at MV

$p_{h} \quad$ Proportionality factor for harmonic order $h$

$S_{i} \quad$ Agreed apparent power of the installation $i$

$S_{O S} \quad$ Harmonic load of the installation

$S_{s c} \quad$ Short circuit power at the point of evaluation

$T H D_{i} \quad$ Total harmonic distortion of the installation $i$

$T H D_{I_{A}} \quad$ Total demand distortion of the installation $i$

$T_{h M L} \quad$ Transfer coefficient of harmonic voltage distortion from upstream MV system to the LV system of the harmonic voltage of order $h$

$U_{h B} \quad$ Harmonic voltage of order $h$ at the substation LV busbar

$U_{h i} \quad$ Harmonic voltage of order $h$ at the point of evaluation of the installation $i$

$V_{\text {droop }} \quad$ Maximum system voltage droop

$x_{i 1} \quad$ Fundamental reactance at the point of evaluation of the installation $i$

$Z_{h B} \quad$ Harmonic impedance of the system at the LV substation busbar

$Z_{h i} \quad$ Harmonic impedance of the system at the point of evaluation of the installation $i$

$\alpha \quad$ Summation law exponent
} 


\section{REFERENCES}

[1] R.C. Dugan, M.F. McGranaghan, S. Santoso and H.W. Beaty, "Electrical Power Systems Quality", Second Ed., McGraw Hill., 2002.

[2] "Electromagnetic compatibility (EMC) - Part 3-14: Assessment of emission limits for the connection of disturbing installation to LV power systems", IEC Technical Report 61000-3-14, Ed. 1.0, 2011.

[3] "Technical Rules for the Assessment of Network Disturbances", 2nd Edition, 2007.

[4] "Recommended Practice for Harmonic Control in Electrical Power Systems", IEEE Std 519-1992, 1992.

[5] R.A. Barr and V.J. Gosbell, "Introducing power system voltage droop as a new concept for harmonic current allocation", 14th International Conference on Harmonics and Quality of Power, ICHQP 2010, BergamoItaly, 26-29 Sept. 2010,

[6] "Electromagnetic compatibility (EMC) - Parts 2-2: Environment - Compatibility levels for low-frequency conducted disturbances and signaling in public low-voltage power supply systems", IEC 61000-2-2, Ed. 2.0, 2002.

[7] "Electromagnetic compatibility (EMC) - Part 3-6: Limits - Assessment of emission limits for distorting loads in MV and HV power systems", IEC Technical Report 61000-3-6, Ed. 1.0, 1996.

[8] Germain Beaulieu, Robert Koch, Mark Halpin and Luc Berthet, "Recommended methods of determining power quality emission limits for the installations connected to EHV,HV,MV and LV power systems", 19th International Conference on Electricity Distribution, paper 0893 , Vienna, 21-24 May 2007.

[9] "Electromagnetic compatibility (EMC) - Parts 3-2: Limits - Limits for harmonic current emissions (equipment input current (16 A per phase)", IEC 61000-3-2, Ed. 3.0, 2005.

[10] "Electromagnetic compatibility (EMC) - Parts 3-12: Limits - Limits for harmonic currents produced by equipment connected to public lowvoltage systems with input current $\geq 16 \mathrm{~A}$ and $\leq 75$ A per phases", IEC 61000-3-12, Ed 1.0, 2004.

[11] Ueli Ammeter, Jaroslav Hanzlik, Jan Meyer and Josef Zierlinger, "Methods for the assessment of emission levels for disturbing installations connected to low and medium voltage networks", 20th International Conference on Electricity Distribution, paper 0248, Prague, 8-11 June 2009.

[12] J. Meyer, U. Ammeter, J.Hanzlik and J.Zierlinger, "Methods for the Assesment of Network Disturbances in Distribution Networks", 13th International Conference on Harmonics and Quality of Power, ICHQP 2008, Wollongong-Australia, 28th Sept. - 1st Oct. 2008.

[13] V.J. Gosbell and R.A. Barr, "A new approach to harmonic allocation for MV installations", 20th Australasian Universities Power Engineering Conference, AUPEC, Christ Church-New Zealand, 5-8 Dec. 2010.

[14] V.J. Gosbell and R.A. Barr, "Harmonic allocation following IEC guidelines using the voltage droop concept," 14th International Conference on Harmonics and Quality of Power, ICHQP 2010, Bergamo-Italy, 26-29 Sept. 2010,

[15] P.F. Ribeiro, "Common misapplications of the IEEE 519 harmonic standard: Voltage or current limits", Power and Energy Society General Meeting - Conversion and Delivery of Electrical Energy in the 21st Century, 20-24 July 2008.

[16] S.M.Halpin, "Comparison of IEEE and IEC harmonic standards", Power Engineering Society General Meeting, 12-16 June 2005.
P. Ciufo (SM'2007) graduated from the University of Wollongong with a B.E. (Hons) in Electrical Engineering in 1990 whilst also completing an Industry Cadetship. He obtained an M.E. (Hons) in Electrical Engineering in 1993. He joined the academic staff of the University after completing his Ph.D. in 2002. Dr Ciufo has had various stints in industry as an Electrical Engineer and returned to academia in 2007. His research interests include Modelling and Analysis of Power Distribution Systems, Advanced Distribution Automation, Modelling and Analysis of AC Machines, Power System Harmonics and Power System Reliability.

V. J. Gosbell (M'1975) obtained his B.SC., B.E. and Ph.D. degrees from the University of Sydney. He has held academics positions at the University of Sydney and the University of Wollongong where he became the foundation Professor of Power Engineering. He is now Emeritus Professor and Technical Advisor to the Endeavour Energy Power Quality and Reliability Centre. He is currently working on harmonic management, power quality monitoring and standards. He is a member of Australian standards and CIGRE sub-committees and is a Fellow of the Institution of Engineers, Australia.
D. Perera (S'2008) received the B.Eng. (Hons.) degree in electrical power engineering from the University of Moratuwa, Sri Lanka, and is currently pursuing the Ph.D. degree at the University of Wollongong, Wollongong, Australia

S. Perera (M'1995) received the B.Sc.(Eng) degree in electrical power engineering from the University of Moratuwa, Sri Lanka, a M.Eng.Sc. degree from the University of New South Wales, Australia, and the Ph.D. degree from the University of Wollongong, Australia. He has been a lecturer at the University of Moratuwa, Sri Lanka. Currently he is an Associate Professor with the University of Wollongong. He is the Technical Director of the Endeavour Energy Power Quality and Reliability Centre at the University of Wollongong. 